\title{
An appraisal of the use of an infrared digital monitoring system for long-term measurement of heart rate in reptilian embryos is
}

\author{
Marina R. Sartori a , Edwin W. Taylor ${ }^{\mathrm{a}, \mathrm{b}}$, Augusto S. Abe a, Dane A. Crossley II c,* \\ a Departamento de Zoologia, Instituto de Biociências, Universidade Estadual Paulista, Campus Rio Claro, SP, Brazil \\ b School of Biosciences, University of Birmingham, B15 2TT, UK \\ c Department of Biological Sciences, Developmental Integrative Biology Cluster, University of North Texas, Denton, TX 76203-5017, USA
}

\section{A R T I C L E I N F O}

\section{Article history:}

Received 20 April 2015

Received in revised form 2 June 2015

Accepted 4 June 2015

Available online 16 June 2015

\section{Keywords:}

Reptiles

Embryonic development

Heart rate

Buddy ${ }^{\circledR}$

Infrared radiation

Temperature

\begin{abstract}
A B S T R A C T
Measurement of heart rate $\left(f_{\mathrm{H}}\right)$ in embryonic reptiles has previously imposed some degree of invasive treatment on the developing embryo. Recently a non-invasive technique of $f_{\mathrm{H}}$ detection from intact eggs was developed for commercial avian breeders and has since been used in biological research. This device uses infrared light, enabling it to detect heartbeats in very early embryos. However, infrared light is a source of heat and extended enclosure of an egg in the device is likely to affect temperature with consequent effects on physiological processes, including $f_{\mathrm{H}}$. We studied the effect of use of the monitor on the temperature of eggs and on $f_{\mathrm{H}}$ in two species of reptiles, the snapping turtle (Chelydra serpentina) and the green iguana (Iguana iguana). Egg temperature increased from a room temperature of $27-28^{\circ} \mathrm{C}$, by $26 \%$ in turtles and $14 \%$ in iguanas over $1 \mathrm{~h}$ of enclosure, resulting in an increase in $f_{\mathrm{H}}$ of $76-81 \%$ in turtles and $35-50 \%$ iguanas. These effects on $f_{\mathrm{H}}$ can either be avoided by brief enclosure of each egg in the monitor or measured and accounted for during the design of long-term experiments. (c) 2015 Elsevier Inc. All rights reserved.
\end{abstract}

\section{Introduction}

Heart rate $\left(f_{\mathrm{H}}\right)$ during embryonic development has been the most commonly reported cardiovascular variable taken from a wide range of species of reptile, providing basic data regarding the maturation of cardiovascular function (Crossley et al., 2003; Crossley and Burggren, 2009; Eme et al., 2011; Sartori et al., 2015). Methods to acquire these data include direct measurements of arterial pressure (Crossley et al., 2003; Crossley and Altimiras, 2005; Eme et al., 2011; Alvine et al., 2013; Eme et al., 2013; Eme and Crossley, 2015), visual counting via a dissecting microscope (Nechaeva et al., 2007; Sartori et al., 2015) or impedance measurements (Bichard and Reiber, 1996; Crossley and Burggren, 2009). While these methods are useful for gathering information regarding maturation of the cardiovascular system they require some degree of invasive instrumentation, possibly disturbing and most often terminating embryogenesis for the individual embryo. Recent longitudinal studies of $f_{\mathrm{H}}$ prior to hatching in embryos of several species of lizards and turtles have utilized a noninvasive method for monitoring $f_{\mathrm{H}}$ using the transmittance or reflectance of infrared light

\footnotetext{
is M.R.S is a postgraduate student in the laboratory of A.S.A. and performed the experiments and analyzed the data; D.A.C. initiated the study and supervised the work on turtles; E.W.T. inspected the data and amended the manuscript.

* Corresponding author at: Department of Biological Sciences, Developmental Integrative Biology Cluster, University of North Texas, Denton, TX 76203-5017, USA
}

from a digital egg monitoring system (Buddy ${ }^{\circledR}$, Avitronics, Truro, UK). Publications using this system include: Lierz et al. (2006), Radder and Shine (2006), Du and Shine (2008), Du et al. (2009), Du and Shine (2010), Du et al. (2010a), Du et al. (2010b), Du et al. (2010c), Du et al. (2010d), Du et al. (2011), McGlashan et al. (2012), Spencer (2012), Angilletta et al. (2013), Aubret (2013), Loudon et al. (2013), Zhao et al. (2013), and Sartori et al. (2015). Infrared radiation (IRR) is an important source of heat (Herschel, 1801: Seigel et al., 2001) and devices emitting IRR are commonly used as a deliberate heating source. If the IRR emitted by the Buddy ${ }^{\circledR}$ system significantly alters the thermal environment of the egg it is likely to affect physiological processes, including $f_{\mathrm{H}}$. Thus, there is clearly the potential for reporting unreliable data on progressive changes in $f_{\mathrm{H}}$ using this system. However, the potential heating effect of infrared light on the thermal status of reptilian eggs was not overtly considered in previous studies and has yet to be determined.

This investigation set out to characterize the changes in heart rate in the embryonic snapping turtle (Chelydra serpentina) and green iguana (Iguana iguana), when exposed to IRR. The snapping turtle represents one of the most extensively studied reptiles during embryonic development, allowing cross study and method comparisons within a species. We hypothesized that the infrared detection method would heat the turtle egg resulting in an elevation in heart rate. To test this hypothesis we studied embryonic snapping turtles at $70 \%$ and $90 \%$ of incubation and green iguanas from $30 \%$ of incubation until close to hatching. The 
eggs of green iguanas increase in mass during development (Sartori et al., 2015), possibly affecting their response to any heating effect from the infrared monitor.

\section{Material and methods}

\subsection{Experimental animals}

\subsubsection{Snapping turtle}

On June 2013 eggs from snapping turtles, C. serpentina were collected in northwestern Minnesota (Minnesota Department of Natural Resources Permit No. 18337 to DAC) and transported to the Biology Department at the University of North Texas, Denton, USA, where the experiments were performed. Upon arrival, eggs were numbered, weighed and placed in plastic boxes (volume approximately 3 1) containing vermiculite mixed with water in a $1: 1$ ratio by mass. Water content of vermiculite was maintained by weighing boxes twice weekly and adding water as needed. The boxes were set in plastic Ziploc bags supplied with normoxic air $\left(21 \% \mathrm{O}_{2}\right)$ bubbled through water to maintain both oxygen and water saturation at adequate levels. The bags were maintained in incubators set to $30{ }^{\circ} \mathrm{C}$. Six eggs from different clutches were taken from incubators at each $70 \%$ and $90 \%$ of incubation time and weighed before assigned to the experiments.

\subsection{Green iguana}

Freshly laid eggs of green iguana, I. iguana were collected during the months of September and October of 2013 from captive gravid females that were part of the breeding program operating at the Jacarezário, Departamento de Zoologia, São Paulo State University (UNESP), Rio Claro, SP, Brazil. Eggs were weighed and immediately placed in trays $(38 \times 28.5 \times 6.5 \mathrm{~cm})$ containing water saturated vermiculite held at a constant temperature of $30 \pm 0.5^{\circ} \mathrm{C}$ in incubators (Eletrolab, EL101/3, SP, Brazil). All eggs were examined daily for signs of mortality and the vermiculite was sprayed with dechlorinated tap water to maintain humidity high. Six eggs were selected from different clutches at the developmental times of: $30 \%, 50 \%, 70 \%, 90 \%$ and just prior to hatching.

\subsection{Instrumentation}

Experiments were performed according to approved animal care protocols (UNT IACUC 11-007 and CEUA-UNESP no. 6597 and no. 3680). The study utilized a digital egg monitor (Buddy ${ }^{\circledR}$ System, Avitronics, Truro, UK) that records $f_{\mathrm{H}}$ non-invasively by detecting movement via infrared sensors, and amplifies the resulting signal, enabling recordings to be obtained from early embryos. The digital egg monitors used in this study were customized by the manufacturers to provide an analog output signal via a BNC connector that was digitally transformed using a data acquisition system (PowerLab; ADInstruments, Bella Vista, NSW, Australia).

For temperature measurement, both snapping turtle and green iguana eggs were weighed and candled to detect a place for insertion of a thermocouple through the eggshell that avoided direct contact with the embryo or yolk. A patch of $1 \mathrm{~cm}^{2}$ of latex glove was attached to the eggshell using cyanoacrylate glue (Loctite, USA). The eggshell was then punctured, through this patch, with a 26-gauge needle, and a flexible implantable thermocouple probe (BAT-4, Physitemp Instruments, NJ, USA or T-type, ADInstruments) was inserted approximately $5 \mathrm{~mm}$ into the egg. Eggs were then placed in the Buddy ${ }^{\circledR}$ chamber which was housed in a constant temperature chamber (EGC, OH, USA/Caltech EIP-010, PE, Brazil) held at $30 \pm 0.5{ }^{\circ} \mathrm{C}$ and the lid of the instrument was closed following the manufacturer's directions for use. Iguana eggs were surrounded by a ring of wet gauze in order to minimize evaporative water loss. The signal outputs from the egg monitors and from the thermocouples in the eggs and in the environmental chambers were relayed to the data acquisition system, (ADInstruments, PowerLab), and recorded simultaneously and continuously via LabChart software (ADInstruments, Bella Vista, NSW, Australia). Recordings were closely monitored and conducted until no major changes in temperature were detected, after a minimum of $2 \mathrm{~h}$. Egg temperature and $f_{\mathrm{H}}$ were collected every $10 \mathrm{~min}$ from the recordings for statistical determination of the time elapsed until stabilization of egg temperature and relationships between temperature and $f_{\mathrm{H}}$ (Table 1$)$. Temperature coefficients $\left(\mathrm{Q}_{10}\right)$ were calculated according to the following equation:

$\mathrm{Q} 10=\left(\frac{\mathrm{R} 2}{\mathrm{R} 1}\right)^{\frac{10}{12-T T}}$

\subsection{Statistical analysis}

Egg mass, initial and final temperatures ( $\mathrm{T}_{\min }$ and $\mathrm{T}_{\max }$ respectively) and initial and final $f_{\mathrm{H}}\left(\mathrm{I} f_{\mathrm{H}}\right.$ and $\mathrm{F} f_{\mathrm{H}}$, respectively) were tested within turtles with paired T-test and within iguanas with one-way ANOVA. A repeated measures ANOVA with time as the independent factor and temperature as the dependent factor was used to detect the point of stabilization of egg temperature. A post hoc Student-Newman-Keuls test was used to identify possible significant differences between the incubation groups. Linear regression analysis was performed with changes in egg temperature (independent variable) and $f_{\mathrm{H}}$ (dependent variable) at each point of incubation period. Tests for snapping turtle data were performed with the STATISTICA version 12 software package and for iguana data with SigmaPlot version 10.0. Significance was attributed at a level of $95 \%$ confidence. Data are presented as mean \pm SEM.

\section{Results}

Eggs left inside the Buddy ${ }^{\circledR}$ warmed with time until they had reached a stable temperature, which was approximately $34^{\circ} \mathrm{C}$ in snapping turtle embryos (Fig. 1A) and to $32{ }^{\circ} \mathrm{C}$ in green iguana (Fig. 1B). A summary of the data for each species and developmental group is detailed on Table 1.

In the turtle egg mass increased from $12.0 \pm 0.8 \mathrm{~g}$ at $70 \%$ incubation to $12.9 \pm 0.3 \mathrm{~g}$ at $90 \%$ incubation, an increase of $7.5 \%$. Temperature stabilization occurred 40 min after the egg monitor was turned on at $70 \%$ incubation and $50 \mathrm{~min}$ at $90 \%$. The mean temperature recorded after a period of $140 \mathrm{~min}$ was $34.0 \pm 0.1^{\circ} \mathrm{C}(\mathrm{n}=6)$ at $70 \%$ and $34.0 \pm 0.2^{\circ} \mathrm{C}$ $(\mathrm{n}=6)$ at $90 \%$. The increasing temperature had a direct effect upon $f_{\mathrm{H}}$. At $70 \%$ mean $f_{\mathrm{H}}$ increased from $55 \pm 1$ (beat $\min ^{-1}$ ) to $96 \pm 3$ (beat $\min ^{-1}$ ), which represents a $76 \%$ increase. At $90 \%$ mean $f_{\mathrm{H}}$ increased from $45 \pm 3$ (beat $\mathrm{min}^{-1}$ ) to $85 \pm 1$ (beat $\mathrm{min}^{-1}$ ), representing $89 \%$ increase. Initial and final $f_{\mathrm{H}}$ of turtles were lower at $90 \%$ of incubation when compared to values at $70 \%$ incubation (Table 1 ). Calculated temperature coefficients $\left(Q_{10}\right)$ were 2.4 and 2.5 for $70 \%$ and $90 \%$, respectively. A linear relationship between $f_{\mathrm{H}}$ and temperature of turtle eggs was strongly supported by data analysis at both $70 \%$ incubation $\left(R=0.90 ; R^{2}=0.82 ; P<\right.$ 0.001 ) and at $90 \%$ incubation $\left(R=0.84 ; R^{2}=0.70 ; P<0.001\right)$ (Fig. $\left.2 A\right)$. $f_{\mathrm{H}}$ increased according to the following equations:

$$
\begin{aligned}
& 70 \%: f_{\mathrm{H}}=6.4 \mathrm{~T}-123.7 \\
& 90 \%: f_{\mathrm{H}}=6.5 \mathrm{~T}-131.3 .
\end{aligned}
$$

In the green iguana egg mass increased from $22.7 \pm 1.8 \mathrm{~g}$ at $30 \%$ incubation to $33.8 \pm 0.1 \mathrm{~g}$ immediately prior to hatching at $100 \%$ incubation, an increase of almost $50 \%$. The increase in egg size was statistically different from initial values at $70 \% 90 \%$ and $100 \%$ of incubation (Table 1 ). Data on egg temperatures and $f_{\mathrm{H}}$ for each of the embryonic periods tested are provided in Table 1. Temperature stabilized after $60 \mathrm{~min}$ at $30 \%$, $50 \%$ and $90 \%$ of incubation, after $70 \mathrm{~min}$ at $70 \%$ and after $80 \mathrm{~min}$ at $100 \%$ incubation (Fig. 1B). As the resultant mean values of $f_{\mathrm{H}}$ with 
Table 1

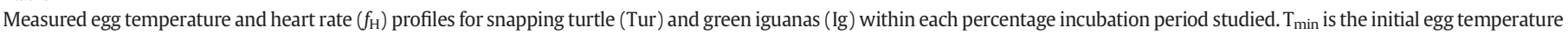

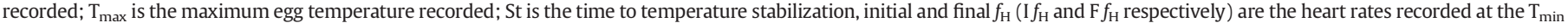

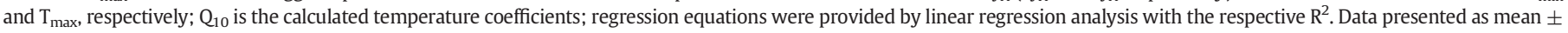
SEM. Statistical significance $(\mathrm{P}<0.001)$ is represented by lower case letters in turtles and capital letters for iguanas.

\begin{tabular}{|c|c|c|c|c|c|c|c|c|c|}
\hline Group & Egg mass ( $\mathrm{g})$ & $\mathrm{T}_{\min }\left({ }^{\circ} \mathrm{C}\right)$ & $\mathrm{T}_{\max }\left({ }^{\circ} \mathrm{C}\right)$ & St $(\min )$ & $\begin{array}{l}\text { If }_{\mathrm{H}} \\
\text { (beat } \min ^{-1} \text { ) }\end{array}$ & $\begin{array}{l}\mathrm{Ff}_{\mathrm{H}} \\
\text { (beat } \min ^{-1} \text { ) }\end{array}$ & $Q_{10}$ & Regression equation & $\mathrm{R}^{2}$ \\
\hline Tur & $12.0 \pm 0.8^{\mathrm{a}}$ & $27.6 \pm 0.2^{\mathrm{a}}$ & $34.0 \pm 0.1^{\mathrm{a}}$ & 40 & $54 \pm 1^{\mathrm{a}}$ & $96 \pm 3^{a}$ & 2.4 & $f_{\mathrm{H}}=6.4 \mathrm{~T}-123.7$ & 0.82 \\
\hline Tur 90 & $12.9 \pm 0.3^{\mathrm{a}}$ & $27.2 \pm 0.4^{\mathrm{a}}$ & $34.0 \pm 0.2^{\mathrm{a}}$ & 50 & $45 \pm 3^{b}$ & $85 \pm 1^{b}$ & 2.5 & $f_{\mathrm{H}}=6.5 \mathrm{~T}-131.3$ & 0.70 \\
\hline $\operatorname{Ig} 30$ & $22.7 \pm 1.8^{\mathrm{A}}$ & $27.4 \pm 0.4^{\mathrm{A}}$ & $32.0 \pm 0.2^{\mathrm{A}}$ & 60 & $70 \pm 3^{A}$ & $104 \pm 7^{\mathrm{A}}$ & 2.4 & $f_{\mathrm{H}}=10.1 \mathrm{~T}-217.7$ & 0.73 \\
\hline $\operatorname{Ig} 50$ & $25.0 \pm 0.9^{\mathrm{A}}$ & $27.7 \pm 0.3^{\mathrm{A}}$ & $31.4 \pm 0.2^{\mathrm{A}}$ & 60 & $69 \pm 4^{\mathrm{A}}$ & $104 \pm 3^{A}$ & 3.0 & $f_{\mathrm{H}}=10.5 \mathrm{~T}-228.8$ & 0.96 \\
\hline $\lg 70$ & $31.6 \pm 1.2^{\mathrm{B}}$ & $28.1 \pm 0.4^{\mathrm{A}}$ & $32.0 \pm 0.2^{\mathrm{A}}$ & 70 & $73 \pm 2^{\mathrm{A}}$ & $109 \pm 3^{A}$ & 2.8 & $f_{\mathrm{H}}=8.1 \mathrm{~T}-155.5$ & 0.78 \\
\hline $\operatorname{Ig} 90$ & $33.2 \pm 0.9^{\mathrm{B}}$ & $28.2 \pm 0.7^{\mathrm{A}}$ & $31.9 \pm 0.2^{\mathrm{A}}$ & 60 & $79 \pm 2^{\mathrm{A}}$ & $107 \pm 4^{\mathrm{A}}$ & 2.3 & $f_{\mathrm{H}}=5.1 \mathrm{~T}-60.3$ & 0.42 \\
\hline $\operatorname{Ig} 100$ & $33.8 \pm 0.1^{\mathrm{B}}$ & $29.3 \pm 0.2^{\mathrm{A}}$ & $32.2 \pm 0.2^{\mathrm{A}}$ & 80 & $72 \pm 4^{\mathrm{A}}$ & $100 \pm 3^{A}$ & 3.1 & $f_{\mathrm{H}}=8.5 \mathrm{~T}-174.4$ & 0.77 \\
\hline
\end{tabular}

time were statistically similar we have reported the combined data. The combined mean temperature after stabilization for all periods of incubation was $31.9 \pm 0.1^{\circ} \mathrm{C}$. Temperature affected $f_{\mathrm{H}}$ directly. The overall

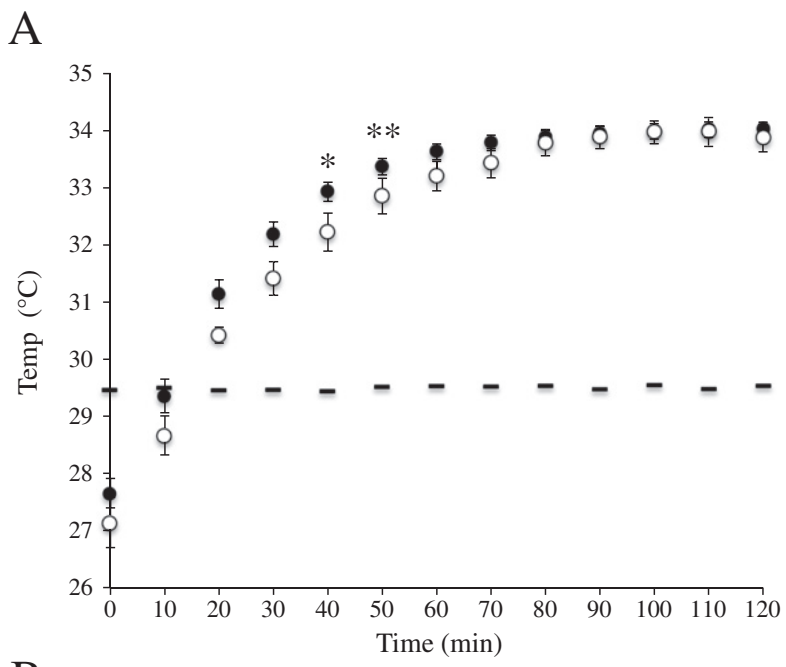

B

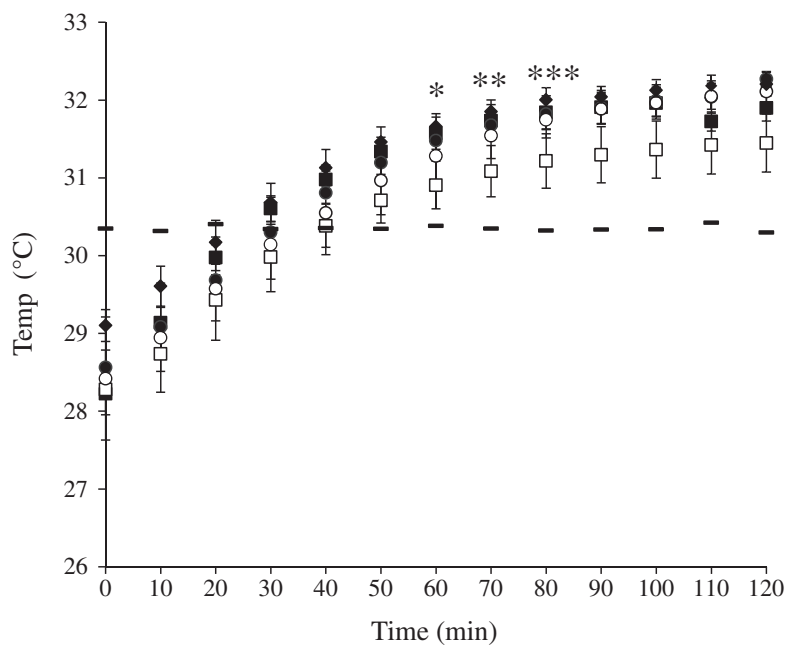

Fig. 1. Profile of temperature change over time for A) snapping turtle egg measured at $70 \%$ (closed circle) and $90 \%$ (open circle) of incubation and B) green iguana eggs measured at $30 \%$ (closed square), 50\% (open square), 70\% (closed circle) 90\% (open circle) and 100\% (closed diamond) of incubation. The dashed line represents mean chamber temperature measured in all periods of incubation. Time zero represents the point of the first reliable measurement of heart rate. Snapping turtle egg temperature changed significantly until $40 \mathrm{~min}$ at $70 \%$ incubation (indicated by a single asterisk) and until $50 \mathrm{~min}$ at $90 \%$ (indicated by a double asterisk). Egg temperature from green iguanas changed significantly until $60 \mathrm{~min}$ (indicated by a single asterisk) at 30\%, 50\% and $90 \%$ of incubation. At $70 \%$ the temperature changed significantly until $70 \mathrm{~min}$ (indicated by a double asterisk) and at $100 \%$ until $80 \mathrm{~min}$ (indicated by a triple asterisk). Data are presented as mean $\pm \mathrm{SEM}$. mean combined $f_{\mathrm{H}}$ increased from $73 \pm 1$ to $105 \pm 2$ (beat $\min ^{-1}$ ), representing an average increase of $44 \%$ (range of $35-50 \%$ ). The combined temperature coefficient $\left(\mathrm{Q}_{10}\right)$ was calculated as 2.8 . The linear
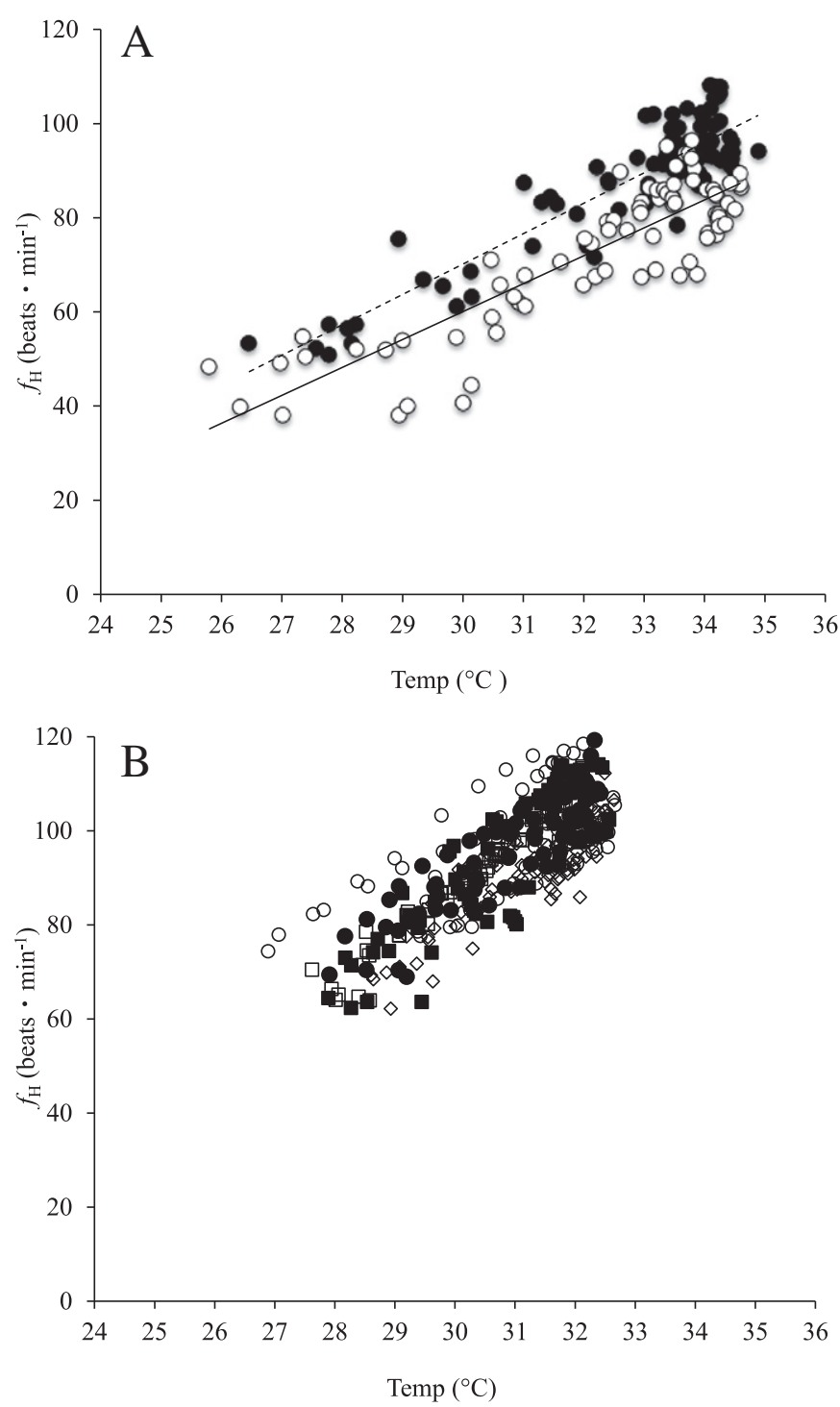

Fig. 2. Pooled heart rate $\left(f_{\mathrm{H}}\right)$ responses for all embyros to increasing egg temperature (Temp) for A) snapping turtle eggs measured at 70\% (closed circle) and 90\% (open circle) of incubation and B) green iguana eggs measured at 30\% (closed square), 50\% (open square), $70 \%$ (closed circle) $90 \%$ (open circle) and 100\% (closed diamond) of incubation. Data points represent $f_{\mathrm{H}}$ for all animals included in the regression for each age group. Linear regression lines for the $70 \%$ (dashed line) and the $90 \%$ (solid line) are presented for the turtles only. For clarity purposes statistical analysis results are presented in Table 1. 
regression of the combined data for all periods of incubation tested indicates a positive linear relationship between $f_{\mathrm{H}}$ and temperature $\left(\mathrm{R}=0.80 ; \mathrm{R}^{2}=0.65 ; \mathrm{P}<0.001\right)$ (Fig. $\left.2 \mathrm{~B}\right)$ that follows the equation:

$f_{\mathrm{H}}=7.9 \mathrm{~T}-150.0$.

\section{Discussion}

The Buddy ${ }^{\circledR}$ monitor is a very effective non-invasive system for documenting embryonic viability, apparently delivering everything that the company (Avitronics, Truro, UK) describes on its web site. They state that it is the first digital egg monitor in the world. Using infrared transmitters and sensors it is capable of amplifying the "cardiovascular signal" of an embryo within the egg by as much as 20,000 times, allowing detection of the heartbeat of the embryo as early as 5 days after incubation has started. The monitor gives a digital read out of $f_{\mathrm{H}}$ onto a small screen. As such it gives the bird breeder "warming knowledge that everything is fine" with their valuable embryos. The company cautions that eggs may cool after removal from the nest and in a trial run they recorded $f_{\mathrm{H}}$ within the Buddy ${ }^{\circledR}$ as reducing from 260 to 190 (beat $\min ^{-1}$ ) within $5 \mathrm{~min}$. What they do not mention is the physical warming effect of the Buddy ${ }^{\circledR}$ upon the eggs that we illustrate above. This will, of course, not be a problem for the bird breeder who merely wants to check the vitality of the egg by briefly placing it in the monitor. Neither is it a problem with the bulk of the experimental biologists that have checked embryo $f_{\mathrm{H}}$ from time-to-time by briefly placing them in the monitor. However, long-term measurements intended to establish how $f_{\mathrm{H}}$ changes during development in a given species must account for and document the heating effects of the system. In our studies these effects were observed during the first hour of enclosure within the Buddy ${ }^{\circledR}$ system. Turtle eggs warmed from $27^{\circ} \mathrm{C}$ to $34^{\circ} \mathrm{C}$, causing an increase in $f_{\mathrm{H}}$ of about $80 \%$. This relatively large warming effect may relate to the size of the eggs and the fact that they were placed directly in the monitor, with no protection against desiccation. Iguana eggs warmed from room temperature of $28{ }^{\circ} \mathrm{C}$ with a $f_{\mathrm{H}}$ of around 73 (beats $\mathrm{min}^{-1}$ ) up to a stabilized rate of about 105 (beat $\mathrm{min}^{-1}$ ) at a temperature of $32{ }^{\circ} \mathrm{C}$, taking between 60 and $80 \mathrm{~min}$ to stabalize. This reduced warming effect may again relate to the relative size of the eggs and to the fact that they were protected against desiccation by being encircled by a wet gauze. Recorded differences in the stabilization times of iguana egg temperatures indicated an apparent trend for smaller eggs to warm faster. The $70 \%$ incubation turtle egg weighing around $12 \mathrm{~g}$ took half the time of a $100 \%$ incubation iguana egg at around $34 \mathrm{~g}$ to stabilize. When we measured some eggs with the lid of the Buddy ${ }^{\circledR}$ held open the temperature of the eggs remained below $30^{\circ} \mathrm{C}$, with the heart beating at around 75 (beats $\mathrm{min}^{-1}$ ), despite being held in an incubator set at $30^{\circ} \mathrm{C}$. Clearly, any investigation of long-term changes in $f_{\mathrm{H}}$ using enclosure of eggs within the Buddy ${ }^{\circledR}$ system must account for the warming effect. In most other studies using the Buddy ${ }^{\circledR}$ system (see Introduction) $f_{\mathrm{H}}$ was measured by brief enclosure of the egg in the monitor. For example, Du and Shine (2008) enclosed each egg for $2 \mathrm{~min}$. However, McGlashan et al., (2012) when exploring the phenomenon of synchronous hatching in turtle embryos, subjected batches of eggs to different temperatures for 7 days then combined them at a set temperature or at a complex series of fluctuating temperatures and measuring outcome as hatching times and post-hatching development and growth. Metabolic compensation by embryos was measured as rate of carbon dioxide production and heart rate. To measure heart rate individual eggs were enclosed in a Buddy ${ }^{\circledR}$ egg monitor and a digital camera was used to record heart rate at 5 min intervals over 30 min with $f_{\mathrm{H}}$ taken as the average over this period. If the egg remained in the monitor throughout the 30 min period then it would have been subject to a similar heating effect to that recorded from turtle eggs in the present investigation. For eggs held at $26{ }^{\circ} \mathrm{C}$ the warming effect may have raised temperature to $31{ }^{\circ} \mathrm{C}$. This implies that $f_{\mathrm{H}}$ was not measured under a steady-state regime and, assuming a $\mathrm{Q}_{10}$ of 2 , it will have increased up to $37 \%$ during the time of measurement.

\section{Conclusion}

The Buddy ${ }^{\circledR}$ digital egg monitoring system provides a convenient and highly reliable technique for the non-invasive monitoring of $f_{\mathrm{H}}$ in very young bird embryos. For long-term measurements in reptiles it has to be noted that the infrared sensors cause a heating effect, which can have significant effects upon $f_{\mathrm{H}}$. This effect may be a particular problem when studying relatively small eggs as they may heat more rapidly. The heating effect should always be measured and taken into account in the design of experiments and analysis of data or avoided by placing each egg in the monitor for brief periods, which is the intended primary use of the instrument.

\section{Acknowledgments}

We would like to thank the following agencies for financial support of the researchers A.S.A./E.W.T. (FAPESP 2012/06938-8); A.S.A./M.R.S. (FAPESP 2012/16537-0); and D.A.C. (National Science Foundation IOS0845741).

\section{References}

Alvine, T., Rhen, T., Crossley II, D.A., 2013. Temperature-dependent sex determination modulates cardiovascular maturation in embryonic snapping turtles, Chelydra serpentina. J. Exp. Biol. 216 (5), 751-758.

Angilletta Jr., M.J., Zelic, M.H., Adrian, G.J., Hulirman, A.M., Smith, C.D., 2013. Heat tolerance during embryonic development has not diverged among populations of a widespread species (Sceloporus undulatus). Conserv. Physiol. 1, 1-9.

Aubret, F., 2013. Heart rates increase after hatching in two species of natricine snakes. Sci. Rep. 3, 3384.

Birchard, G.F., Reiber, C.L., 1996. Heart rate during development in the turtle embryo: effect of temperature. J. Comp. Physiol. B166 (8), 461-466.

Crossley, D.A., Altimiras, J., 2005. Cardiovascular development in embryos of the American alligator Alligator mississippiensis: effects of chronic and acute hypoxia. J. Exp. Biol. 207, 31-39.

Crossley, D.A., Burggren, W.W., 2009. Development of cardiac form and function in ectothermic sauropsids. J. Morphol. 270 (11), 1400-1412.

Crossley, D.A., Hicks, J.W., Altimiras, J., 2003. Ontogeny of baroreflex control in the American alligator Alligator mississippiensis. J. Exp. Biol. 206, 2895-2902.

Du, W.G., Shine, R., 2008. The influence of hydric environments during egg incubation on embryonic heart rates and offspring phenotypes in a scincid lizard (Lampropholis guichenoti). Comp. Biochem. Physiol. A 151, 102-107.

Du, W.G., Shine, R., 2010. Why do the eggs of lizards (Bassiana duperreyi: Scincidae) hatch sooner if incubated at fluctuating rather than constant temperatures? Biol. J. Linn Soc. 101, 642-650.

Du, W.G., Radder, R.S., Sun, B., Shine, R., 2009. Determinants of incubation period: do reptilian embryos hatch after a fixed total number of heart beats? J. Exp. Biol. 212 1302-1306.

Du, W.G., Thompson, M.B., Shine, R., 2010a. Facultative cardiac responses to regional hypoxia in lizard embryos. Comp. Biochem. Physiol. A 156, 491-494.

Du, W.G., Warner, D.A., Langkilde, T., Robbins, T., Shine, R., 2010b. The physiological basis of geographic variation in rates of embryonic development within a widespread lizard species. Am. Nat. 176 (4), 522-528.

Du, W.G., Zhao, B., Shine, R., 2010c. Embryos in the fast lane: high-temperature heart rates of turtles decline after hatching. PLOS ONE 5 (3).

Du, W.-G., Ye, H., Zhao, B., Warner, D.A., Shine, R., 2010d. Thermal acclimation of heart rates in reptilian embryos. PLOS ONE 5 (12).

Du, W.-G., Ye, H., Zhao, B., Pizzatto, L., Ji, X., et al., 2011. Patterns of interspecific variation in the heart rates of embryonic reptiles. PLoS ONE 6 (12).

Eme, J., Crossley II, D.A., 2015. Short communication: chronic hypercapnic incubation increases relative organ growth and reduces blood pressure of embryonic American alligator (Alligator mississippiensis). Comp. Biochem. Physiol. A 182, 53-57.

Eme, J., Hicks, J.W., Crossley II, D.A., 2011. Chronic hypoxic incubation blunts a cardiovascular reflex loop in embryonic American alligator (Alligator mississippiensis). J. Comp. Physiol. B. 181 (7), 981-990.

Eme, J., Rhen, T., Tate, K.B., Gruchalla, K., Kohl, Z.F., Slay, C.E., Crossley II, D.A., 2013. Plasticity of cardiovascular function in snapping turtle embryos (Chelydra serpentina) chronic hypoxia alters autonomic regulation and gene expression. Am. J. Physiol 304, R966-R979 Regulatory, Integrative, and Comparative Physiology.

Herschel, W., 1801. Observations tending to investigate the nature of the Sun, in order to find the causes or symptoms of its variable emission of light and heat; with remarks on the use that may possibly be drawn from solar observations. Phil. Trans. R. Soc London 91, 265-318.

Lierz, M., Gooss, O., Hafez, H.M., 2006. Noninvasive heart rate measurement using a digital egg monitor in chicken and turkey embryos. J. Avian Med. Surg. 20 (3), 141-146. 
Loudon, F.K., Spencer, R.J., Strassmeyer, A., Harland, K., 2013. Metabolic circadian rhythms in embryonic turtles. Int. Comp. Biol. 53 (1), 175-182.

McGlashan, J.K., Spencer, R.J., Old, J.M., 2012. Embryonic communication in the nest: metabolic responses of reptilian embryos to developmental rates of siblings. Proc. R. Soc. B 279, 1709-1715.

Nechaeva, M.V., Vladimirova, I.G., Alekseeva, T.A., 2007. Oxygen consumption as related to the development of the extraembryonic membranes and cardiovascular system in the European pond turtle (Emys orbicularis) embryogenesis. Comp. Biochem. Physiol. A 148 (3), 599-610.

Radder, R., Shine, R., 2006. Thermally induced torpor in fullterm lizard embryos synchronizes hatching with ambient conditions. Biol. Lett. 2, 415-416.
Sartori, M.R., Leite, C.A.C., Abe, A.S., Crossley II, D.A., Taylor, E.W., 2015. The progressive onset of cholinergic and adrenergic control of heart rate during development in the green iguana, Iguana iguana. Comp. Biochem. Physiol. A 188, 1-8.

Siegel, J.R., Howell, R., Howell, J.R., 2001. Thermal Radiation Heat Transfer. Taylor \& Francis, Inc., New York.

Spencer, R.J., 2012. Embryonic heart rate and hatching behavior of a solitary nesting turtle. J. Zool. 287, 169-174.

Zhao, B., Chen, Y., Wang, Y., Ding, P., Du, W.G., 2013. Does the hydric environment affect the incubation of small rigid-shelled turtle eggs? Comp. Biochem. Physiol. A 164, $66-70$ 